\title{
Induction of Artesunate Resistance in Plasmodium Falciparum 3D7 Strain Using Intermittent Exposure Method and Comparing P.fk13 Sequence between Susceptible and Resistant Strains
}

\section{Sahar Barati}

Tehran University of Medical Sciences

Afsaneh Motevalli Haghi ( $\square$ a-motevalli@tums.ac.ir)

PS IS 78 Robert F Wagner Junior School https://orcid.org/0000-0002-5599-5207

Mehdi Nateghpour

Tehran University of Medical Sciences

Zahra Zamani

Pasteur Institute of Iran

\section{Sadegh Khodaveisi}

Tehran University of Medical Sciences

\section{Soudabeh Etemadi}

Tehran University of Medical Sciences

\section{Research}

Keywords: Malaria, Plasmodium falciparum, parasites, artemisinin

Posted Date: February 4th, 2021

DOI: https://doi.org/10.21203/rs.3.rs-168624/v1

License: (c) (i) This work is licensed under a Creative Commons Attribution 4.0 International License. Read Full License 


\section{Abstract}

Background: Malaria is a major health issues in a number of countries in the world, especially tropical countries. Over the past 50 years, the resistance of Plasmodium falciparum has expanded against the antimalarial drugs that had been used to treat the disease. Recently resistance to some derivatives of artemisinin and the failure of artemisinin combination therapy (ACT) has threatened all major achievements in malaria control. Resistant strains are limited around the world, but it may spread very soon, hence the necessary to be prepared for any event regarding this matter, it is needed to organize more investigations about resistant strains and related genes. Preparation of a new resistant strain in the laboratory can provide opportunity to predict genes responsible for resistance. The aim of this study was to induce resistance to artesunate in Plasmodium falciparum 3D7 strain using intermittent exposure method and comparing P.fk13 gene sequence between susceptible and resistance strains.

Methods: Plasmodium falciparum 3D7 strain was cultured according to Trager \& Jensen method with some modifications. Serial concentrations between $10^{-2} \mathrm{~mol} / \mathrm{l}$, to $10^{-7} \mathrm{~mol} / \mathrm{I}$ were prepared, then P.falciparum 3D7 was exposed to each of the dilution to determine IC50 and lethal dose. After 24 hours exposure the rate of parasitemia and mean of growth inhibitory percent were evaluated. Sensitivity reduction process was started from the concentration of $10^{-7} \mathrm{~mol} / \mathrm{l}$ and ended at $10^{-}$ ${ }^{2} \mathrm{~mol} / \mathrm{l}$. Exposed parasites were collected after at least 27 days after cultivation in each drug concentration. DNA extraction, PCR and sequencing process were performed to investigate any possible mutations in the pfk13 gene sequence.

Results: Effectiveness of $10^{-2} \mathrm{~mol} / \mathrm{l}$ concentration of artemisinin was found as a lethal dose. The resistant strain was provided in the lab, sequenced and registered in the gene bank as P.f Art $^{-2}$, (accession number MH796123. 1). Alignment of this registered sample showed no mutation in P.f kelch13 gene in comparison with standard strain submitted in the Genebank.

Conclusions: Results of this study showed that resistance to artesunate in malaria parasite may occur but with no mutation in the P.f kelch13 gene. Therefore, whole genome sequencing should be applied to determine mutations in resistant strains.

\section{Introduction}

Malaria is an important health issues in a number of countries, especially in tropical and subtropical areas [1]. Malaria is being spread in 90 countries, and about $40 \%$ of the world's population live in areas where there is a risk of malaria transmission[2, 3]. Exposure of 216 million people to malaria and 445,000 deaths in 2017 makes it one of the most important infectious diseases[4]. The resistance of Plasmodium falciparum against some antimalarial drugs such as chloroquine, sulfadoxine-pyrimethamine, quinine, piperquine, and mefloquine has been expanded over the past 50 years. Recently resistance to the some derivatives of artemisinin and the failure of combination therapy with artemisinin (ACT) has threatened all major achievements in malaria control[5]. Delays in clearing parasites from the infected individuals' blood is the first alarm of spreading of malaria resistance in malaria areas that ultimately will lead to a complete failure of treatment. Following frequent historical chain of events that have occurred in the field of drug resistance to malaria, many efforts have been taken to consider such phenomenon. Experimental induction of resistance in malaria parasites against one or more antimalarial drugs and considering results of the process can guide malaria policy makers to make appropriate decisions when they encounter with the real problem. Witkowski et al. reported that the mechanism of resistance to artemisinin can be followed using an empirical model. They developed cell lines, F32-ART, after five years with increasing concentrations of artemisinin exposing to the parasite in the laboratory[6]. The resistance of Plasmodium falciparum to artemisinin was due to the increase in the number of young form of parasite that enters into the phase of inactivation in the presence of the drug. By removing the drug, this form of ring re-enters in the growing phase. They also declared that such phenomenon happens due to the mutation of PfK13 gene of Kelch superfamily. Some authors believe that the gene is currently being pursued to track the role of relevant genes of P.falciparum in resistance to artemisinin [6-8]. Producing a drug resistance line of P.falciparum against artesunate can provide a new field of research for challenging the mentioned

Page 2/17 
problem and can demonstrate likely mutations in the relevant genes. Therefore, the aim of this study was to reduce the sensitivity of $P$. falciparum 3D7 strain to artesunate using intermittent exposure method and comparing the sequence of Pfk13 gene between the sensitive and probable resistant strains.

\section{Materials And Methods Parasite cultivation}

This study was conducted at the National Malaria Laboratory, School of Public Health, Tehran University of Medical Sciences. The procedure was as follow: continues culture of P.falciparum 3D7 was performed according to the Trager and Jenson procedure with some modifications[9]. Briefly, frozen sample of P.falciparum 3D7 was taken out of liquid nitrogen and thawed, then centrifuged at $5000 \mathrm{rpm}$ for one minute, the supernatant was removed, and the sediment was washed twice with Complete Culture Medium (RPMI 1640, human serum AB': 10\%, Hypoxanthine: 50 mg/l, Gentamycin: 50 mg/l (CCM)). The pellet was dropped into a $25 \mathrm{~mm}$ in diameter plate containing CCM medium as well as $10 \%$ of $\mathrm{O}^{+}$human $\mathrm{RBCs}$ hematocrit, and Albumax (0.5\%) were added to each plate as a growth factor for parasites. Plates were placed in a candle jar and incubated at $37^{\circ} \mathrm{C}$. CCM was replaced with fresh medium every 48 hours. Human RBC was added every week to maintain $10 \%$ hematocrit. Thin blood smears were prepared from the sedimentation of each plate and then percentage of parasites was counted against 10000 red blood cells. When the parasitemia reached to 10 percent, artesunate was added to the plates by the following procedure:

\section{Preparation of lethal and sub lethal concentrations of artesunate:}

Artesunate, a white crystalline powder ( $\mathrm{MW}=384.42$, cat No. A3731, sigma Aldrich,) was used for preparing different concentrations for exposing the parasite. The substance was dissolved in $60 \%$ ethanol in PBS to obtain $10^{-2} \mathrm{~mol} / \mathrm{L}$ concentration. This concentration was chosen due to its administration as a lethal dose in comparison with treatment in human. Then the serial dilution of $10^{-3}, 10^{-4}, 10^{-5}, 10^{-6}$ and $10^{-7} \mathrm{~mol} / \mathrm{L}$ were prepared for relevant tests. To define sub lethal dose of drug, IC50 was determined. Drug resistance induction was started using a concentration of lower than IC50.

\section{Determination of artesunate IC50 on P.falciparum 3D7:}

P. falciparum continuous culture was prepared as mentioned above. Lethal dose was rechecked and IC50 was determined. For preparing the IC50 of artesunate against the parasite, serial concentrations of artesunate as: $10^{-4}, 10^{-5}, 10^{-6}, 10^{-7}$, $10^{-8}, 10^{-9}$ and $10^{-10} \mathrm{~mol} / \mathrm{L}$, were made from stock solution $\left(10^{-2} \mathrm{~mol} / \mathrm{L}\right)$ in $\mathrm{CCM}$ under sterile condition and then were frozen in $-20^{\square} \mathrm{C}$ until using time. Drug sensitivity test was conducted in 96-well microtitre plate in comparison with control groups. Each plate was designed as follow: RBCs control (negative control) including $10 \mu$ fresh-washed $0+$ RBC plus 180 $\mu \mathrm{l}$ of CCM. Positive control was charged with $10 \mu$ infected RBC with $6 \%$ parasitemia yield in continuous culture and $180 \mu \mathrm{l}$ of CCM. Groups of 3 to 9 (groups Pi test): $10 \mu \mathrm{l}$ of infected RBC (\%6 parasitemia) plus $90 \mu \mathrm{l} \mathrm{CCM}$ and $100 \mu$ l drug dilution (from $10^{-4} \mathrm{~mol} / \mathrm{l}$ concentration to $10^{-10} \mathrm{~mol} / \mathrm{l}$ for each test respectively). Negative and positive control were respectively designed to check fresh red blood cells and parasite growth enhanced during the incubation. Plates were placed in the candle jar and kept in a $37^{\circ} \mathrm{C}$ incubator for 24 hours. A thin smear was made from sediment of each well after removing liquid culture media. Smears were stained with $5 \%$ Giemsa stain in distilled water about 30 minutes. In the case of control and concentrations, average parasitemia were achieved based on counting infected RBCs against 10.000 RBC. The tests were repeated three times and mean of parasite percentage was calculated. Rate of parasitemia and inhibitory effect of each drug concentration on parasite growth was calculate as following and IC50 was achieved using SPSS software. 


\section{Inhibitory rate $=100-\left(\frac{\text { mean of parasitemia in each test goup }}{\text { mean of parasitemia in control group }} \times 100\right)$}

\section{Induction of drug resistance in P.falciparum 3D7:}

The procedure of establishing drug resistance in P.falciparum against artesunate was accomplished as described by Nateghpour et al, with some modifications[10]. Briefly, parasites in the culture were exposed to the above mentioned concentrations of artesunate. Induction was started from a concentration lower than IC50. In each individual process of tests, $100 \mu \mathrm{l}$ of artesunate was added to $2.5 \mathrm{ml}$ parasitized culture with $10 \%$ hematocrit, while the rate of parasitemia was reached to $6-7 \%$. Every 24 hours the medium removed from the culture, thin blood smear was prepared and fresh CCMartesunate were added. Smears were stained with Giemsa stain and then the rate of parasitemia was calculated. Parasitemia rate was reduced due to effecting the drug on the parasite. At the reduction point of $50 \%$ parasitemia in comparison with control group a free of drug break including normal medium was administrated for those drug exposed parasites. Such alteration resulted in a renewing growth of parasites. This procedure was continued until equivalent parasite growth was achieved in the artesunate treated parasites compared to control. Exposing to the drug continued for about one month (at least 27 days) at which point the drug concentration was increased up to $10^{-2} \mathrm{~mol} / \mathrm{l}$. At the end of each phase of resistance development some of the resisted parasites were preserved in liquid nitrogen for further investigation, also about $200 \mu \mathrm{l}$ of each sample was kept in $-20^{\circ} \mathrm{C}$ for molecular analysis.

\section{Control groups:}

The control group included only the CCM fresh RBC and infected RBC with P.falciparum 3D7, which was not affected with any drug, and growth of the parasite continued until the parasitemia percentage reached $10-12 \%$. The parasite population was divided into two parts to prepare 6-7\% parasitemia in the culture medium for control and test groups. In this step some of the parasites were frozen down in nitrogen liquid for future studies. Percentage of test groups which were under the effectiveness of the drug was compared with this control group. Moreover, a case control was applied for molecular analysis, it was a blood sample achieved from a patient who was infected with $P$. falciparum, but no recovery observed after artesunate administrated, this sample was considerate as a resistante strain to compare with created resistant strain in the lab.

\section{DNA extraction and Nested PCR test:}

Those samples that became resistant against artesunate were selected for DNA extraction processes. The extraction process was performed according to the manufacture instructions (SinaClon, Cat No: EX6001, Lot No: 9660027). Nested PCR method was employed to detect Pfk13 gene. For this purpose two pairs primer were prepared (Table 1) by CinnaGen company based on previous study $[7,11]$. Gene amplification was designed in two steps, the procedure was as follow: a pair of primer including K13F1 and K13R1 were used for the first round. PCR reactions were performed in $25 \mu$ volumes containing $10 \mu \mathrm{l}$ master mix, $1 \mu \mathrm{l}$ of each primer (10 pmol), $10 \mu \mathrm{l}$ distill water and $3 \mu \mathrm{l}$ of DNA template (50 $\mathrm{ng})$ for the first amplification round. Thermocycler program was stabilized after a gradient PCR and finding the best temperature for annealing step, using the following protocol: initial denaturation $94 \rrbracket$ for 5 followed by 40 cycles including denaturation $94 \rrbracket$ for 30 secs, annealing $60 \rrbracket$ for $90 \rrbracket$, extension $72^{\square}$ for $90 \rrbracket$ and last step containing $10^{\prime}$ in $72^{\natural}$ for final extension. For further investigation the resistance sample of P.falciparum from the infected patient was included to this series for comparing samples. In fact, this sample was used as a control for molecular analysis. PCR products were electrophoresed on the agarose gel and a band corresponding to P.falciparum 3D7 P.fk13 gene was detected. 
Table 1

Primers for nested PCR of K13 gene in P. falciparum

\begin{tabular}{|c|c|c|c|c|c|c|c|c|c|}
\hline Name & Seg- $(5-3)$ & MW & $\begin{array}{l}\text { OD } \\
(1000 \\
\mu l)\end{array}$ & $\mathrm{nmol}$ & $\begin{array}{l}\text { Water/tube } \\
(\mu l)\end{array}$ & TM & GC\% & Mer & $\begin{array}{l}\text { Product } \\
\text { size }\end{array}$ \\
\hline K13F1 & GGGAATCTGGTGGTAACAGC & 6222.07 & 2.5 & 13.26 & 132.59 & 59.35 & 55 & 20 & 2097bp \\
\hline K13R1 & CGGAGTGACCAAATCTGGGA & 6191.06 & 4 & 21.32 & 213.21 & 59.35 & 55 & 20 & \\
\hline K13F2 & GCCTTGTTGAAAGAAGCAGA & 6190.07 & 3 & 15.99 & 159.93 & 55.25 & 45 & 20 & $849 b p$ \\
\hline K13R2 & GCCAAGCTGCCATTCATTTG & 6067.94 & 3.5 & 19.03 & 190.34 & 57.30 & 50 & 20 & \\
\hline
\end{tabular}

The PCR product yield from the first stage was used as a template for the second round of amplification. For this purpose, two microliter of products with 1:500 dilutions were prepared and used. The best temperature for annealing step at the second round was detected using PCR gradient. The materials to perform the second round for amplification were as the same in the first round. Horizontal electrophorese was done on $1 \%$ agarose gel to detect and observe the results. The presence of bands was investigated in the U.V Trans illuminator room, a band with 849 bp weight correspond to P.f kelch13 was yield in the second step of nested PCR then photographed using the Gel Documentation System.

\section{Gene sequencing}

In order to determine the sequence of Kelch gene nucleotides in sensitive and reduced sensitivity to artesunate strains and patient specimen, all of the PCR products samples were sent to the Biotechnology Research Center of Germany (MWG) by the SinaClon Company. Samples were sequenced in forward and reverse directions, then were submitted to the GeneBank.

\section{Results}

\section{Parasite cultivation, lethal dose and IC50}

A successful profile cultivation of P.falciparum 3D7 strain has been shown in Fig. 1 with healthy ring and schizont stages. It beared an increase in the number of parasites (Fig. 2. (A)). The concentration of $10^{-2} \mathrm{~mol} / \mathrm{l}$ was known as a lethal dose at the beginning step of the study. As it is presented in Fig. 2. (B), it led to the death of all parasites, while a resistant strain to the same concentration was produced latter.

Table 2 shows the effects of the concentrations of $10^{-4}, 10^{-5}, 10^{-6}, 10^{-7}, 10^{-8}, 10^{-9}$ and $10^{-10} \mathrm{~mol} / \mathrm{I}$ to determine the IC50 of artesunate on the P.falciparum 3D7 parasite. According to Table 2 calculation of the growth inhibitory percent shows the value of IC50 could be between $10^{-4} \mathrm{~mol} / \mathrm{I}$ and $10^{-5} \mathrm{~mol} / \mathrm{I}$, the growth inhibitory percentage in these concentrations was about $56 \%$ and $45 \%$, respectively. So for determining the accurate value of IC50 between two results, these outcomes analyzed using SPSS software to obtain more precise results. Figures 3 shows the results of this analysis that the IC50 value was equal to $5 \otimes 10^{-4} \mathrm{~mol} / \mathrm{l}$. 
Table 2

Inhibitory effectiveness of different dilutions of artesunate on parasite growth to determine IC50. Group 1 (negative control), group 2 (positive control), groups of 3 to 9 (groups Pi test) containing drug dilution (from

$10^{-4} \mathrm{~mol} / \mathrm{l}$ concentration to $10^{-10} \mathrm{~mol} / \mathrm{l}$ in each test respectively).

\begin{tabular}{|lll|}
\hline groups & Drug concentration & Average growth inhibitory percentage \\
\hline 1 & Negative control & - \\
\hline 2 & Positive control & 0 \\
\hline 4 & $10^{-4} \mathrm{~mol} / \mathrm{lit}$ & $56 \%$ \\
\hline 5 & $10^{-5} \mathrm{~mol} / \mathrm{lit}$ & $45.3 \%$ \\
\hline 6 & $10^{-6} \mathrm{~mol} / \mathrm{lit}$ & $40.08 \%$ \\
\hline 7 & $10^{-7} \mathrm{~mol} / \mathrm{lit}$ & $24.61 \%$ \\
\hline 8 & $10^{-8} \mathrm{~mol} / \mathrm{lit}$ & $14.49 \%$ \\
\hline 9 & $10^{-9} \mathrm{~mol} / \mathrm{lit}$ & $11.27 \%$ \\
\hline
\end{tabular}

\section{The results of sensitivity reduction in P. falciparum 3D7 against artesunate using the intermittent exposure method}

When sensitivity reduction test was performed for parasite, the patterns of decreasing and increasing parasitemia in the culture for each concentration (from $10^{-7} \mathrm{~mol} / \mathrm{l}$ to $10^{-2} \mathrm{~mol} / \mathrm{l}$ ) was more or less the same. This pattern of induction of drug resistance has been shown in Fig. 4 (parasitemia percentage was $6-7 \%$ at the beginning of this process). The line of parasite which was successful to growth with the presence of drug, saved and preserved in comparison with control group (Fig. 5). Some times in this process a line of parasite was going to the death completely, so it was coming out of the study automatically (Fig. 6).

\section{Molecular analysis}

The results of gene proliferation, from P.falciparum 3D7 using the Nested PCR method showed a 2097bp band corresponding to P.f kelch13 gene at the first round. Figure 7 shows first stage amplification from seven samples including P.falciparum 3D7 which was sensitive to artesunate, four new strains reduced sensitivity to artesunate with concentration of $10^{-5} \mathrm{~mol} / \mathrm{l}, 10^{-4} \mathrm{~mol} / \mathrm{l}, 10^{-3} \mathrm{~mol} / \mathrm{l}, 10^{-2} \mathrm{~mol} / \mathrm{l}$, a sample from the patient who showed resistance reaction to artesunate administration and finally the Negative Control. In the second round of amplification an 849 bp band related to the middle part of kelch13 gene was created and sequenced for molecular analysis (Fig. 8).

\section{P. $f$ kelch13 gene sequencing}

Gene sequencing was performed for all products of $P . f$ kelch 13 gene on PCR product yield from second round, but

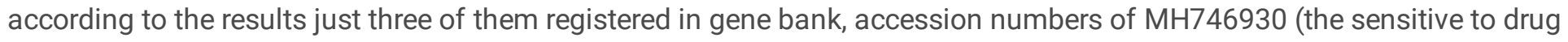
and standard strain), MH796123 (Pfkelch13 $\mathrm{Ar}^{-2}$, which was created in this study and was resistance to artesunate $10^{-2}$ $\mathrm{mol} / \mathrm{I}$ concentration) and MH796124 (Pfkelch13Ar- ${ }^{4}$, a sample from the patient who was resistante to treatment with 
artesunate), it is important to note that the other lines which were created in resistance form to $10^{-5} \mathrm{~mol} / \mathrm{l}, 10^{-4} \mathrm{~mol} / \mathrm{l}, 10^{-3}$ $\mathrm{mol} / \mathrm{I}$ were not registered due to their sequences similarity to Pfkelch $13 \mathrm{Ar}^{-2}$.

Nucleotide alignment was done for nucleotides sequence derived from Pfkelch13 $\mathrm{Ar}^{-2}$, Pfkelch13 $\mathrm{Ar}^{-4}$ and sensitive strain in this study. Results showed no mutation in the relative strengthen lines and also in one patient who showed resistance to artesunate administrating. Clustal multiple sequence alignment showed $100 \%$ Identity (Fig. 9).

\section{Discussion}

Nowadays artemisinin is the most significant choice of anti-malarial drugs for treatment of falciparum malaria infection in the most malarious areas of the world. Reports about resistance to the drug is one of the greatest fears for international attempt to control and eliminate malaria parasites. Producing experimental $P$. falciparum resistant strain against antimalarial drugs in the laboratory provides an invaluable opportunity to investigate the mechanism of parasite resistance to drugs, moreover these strains facilitate investigations about those substances that bears potential antimalarial activities. Previous reports suggested that mutations in the Pf kelch13 gene can be resulted in P.falciparum resistance to artesunate, similarly mutation in this gene was reported as the responsible agent for slow parasite clearance in many cases. It is implied that this gene is the best candidate for the study of nucleotide mutations in the resistance of $P$. falciparum to artesunate [12-14]. On the other hand Mukherjee et al. in 2017 conducted a study at Harvard University, they reviewed the resistance of the parasite to artemisinin in Africa. Despite administration of the standard dosage, patients showed drug resistance of the parasite, but authors clarified that there was no mutation in the kelch $13 \mathrm{gene}$ in spite of resistance to artemisinin. They also claimed that it can be searched the cause of resistance in another gene locus except Pf kelch13[12].

It is recommended that there are other possible genes related to resistance in Plasmodium species. Scientists reported that mutations in pfmdr1, pftctp and PfATPase6 genes can be emerging with presence of higher concentrations of drug and resulted in resistance phenomenon of parasites [15-17]. Identifying the exact mechanism of resistance needs more investigation about those genes that involve in resistance phenomenon. It should be considered that parasites may show conflict with drugs via different ways. Reducing the sensitivity in one strain can be accompanied by over expression of a specific genes involved in the process of inducing resistance and producing a series of proteins and novel substances. As mentioned, resistance can be induced through the cultivation of $P$. falciparum parasite and its long exposure to artemisinin or its derivatives.

In the present study, a new strain of $P$. falciparum was created under the intermittent exposing the parasite to different concentrations of artesunate. The created strain cultured under the drug pressure from the least concentration to the maximum chosen dose for one month; then preserved in liquid nitrogen for further investigation. The line of $\mathrm{Pfkelch} 13 \mathrm{Ar}^{-2}$ was the resistant line for the highest concentration of the drug which is exposed to it $\left(10^{-2} \mathrm{~mol} / \mathrm{l}\right)$. Sequencing of the Pfkelch13 gene derived from produced strain indicated that there is no mutation in comparison with the original ones. This idea was confirmed when compared with the sequence of an isolated sample from an artemisinin treatment failed patient. It should be noted while some previous studies reported that nucleotide changes in this gene are responsible for phenotype resistance, others indicated that other interacting molecules may responsible for this mechanism, therefore, it can be suggested that sensitivity reduction to the drug likely occurred in the line used in this study, but in the Pfkelch13 piece has not happened any mutation.

During the past few years, scientists have tried to produce a resistant parasite line. Some of them used different procedures to produce it, Cui and colleagues in 2012 sought to establish a resistante line to dehydroartemisinin (DHA) in the 3D7 strain. They succeeded to produce of two parasite clones from Dd2 using in vitro method which showed 25-fold reduction in susceptibility to DHA. Moreover they declared that resistance of P.falciparum to dehydroartemisinin firstly occurred in ring stage, then propagate to schizont and trophozoite forms. Their results revealed that redundant proliferation of pfmdr1 
gene locus of this new clone enhances production of antioxidant and expression of a chaperone in parasite. The outcome has important concept for development of ART resistance in Southeast Asia [18].

In general, resistance to artemisinin in $P$. falciparum can be promoted by different mechanisms that can rely on the foundation of the drug. Studies by Witkowski and colleagues in 2013 and 2014 led to the discovery of a mechanism for resistance to artemisinin using an experimental model. Results of the study yield a creation of a cell line called F32-ART, which was produced in the laboratory after 5 years exposure to increasing concentrations of artemisinin. The data from the F32-ART cell line, highly resistant to artemisinin, showed that the pressure of artemisinin induces a stop in extension of very young parasites population in the ring stage, which led to the displacement of this small population toward the silent phase, however, artemisinin kills all the parasites in other phases of the life cycle $[6,19]$. On the other hand, further studies by Straimer et al. in 2015 revealed that mutations in the kelch13 gene was firstly associated with resistance to artemisinin. The authors demonstrated a crucial and fundamental function for K13-propeller mutations related to ART resistance in vitro and explained about molecular feature for slow parasite clearance rates in patients [20].

In a study by Rocamora et al. in 2018, two resistant clones (6A-R and 11C-R) against artemisinin were produced from P.falciparum 3D7 by sequential contacts of synchronized parasite cultures to artemisinin to detect and describe molecular factors that are responsible for resistance of P.falciparum to artemisinin. Both the above mentioned parasite lines showed decreases drug susceptibility and derived resistance phenotype(s) were predominant in the ring stage; although both of them carried the wild-type allele of the K13 gene [21]. Chavchich and his colleague investigated potential mechanisms related to increase of resistance, they declared that $P$. falciparum lines have the ability to improve resistance to artemisinin derivatives in vitro due to multiple mechanisms such as amplification and increased expression of Pfmdr1. The results of the study was difference with other studies which explain that mutations are responsible for resistant phenomen[6, 7, 22].

The method of the present study from this point of view that the parasite is intermittently exposed to drugs, was similar to the Rocamora's study, the parasite was able to be exposed to a concentration of $10^{-2} \mathrm{~mol} / \mathrm{l}$, while sequencing was not showed any mutation in Pf kelch13. Rocamora sequenced the whole parasite genome and found 5 mutations in others than kelch13. The mutation changes that were found by him were related to genes that have an expressive role, such as AP2-like transcription factors, PHD finger protein, and RNA helicase. Of course, both clones produced had wild kelch13 genes confirmed by PCR and genotyping. As it mentioned above, molecular studies and alignment of the Pfkelch13 $\mathrm{Ar}^{-2}$ produced in the present study showed a similarity of $100 \%$ with Kelch13 gene sequence in the susceptible 3D7 strain at the nucleotide level and no mutation was observed at this level [21].

Ten years after using combination therapy based on artemisinin against $P$. falciparum studies in Grande Comore Island released some polymorphisms of resistance markers of artemisinin in kelch13. The results of the study showed that only 3 samples collected from 2006 to 2007 were SNP carriers in the kelch13 gene, one synonymous replacement sample (G538G) and two other non-synonymous replacements (D284E, S477Y) that these replacements led to creating two mutant haplotypes, also, in the obtained samples in the years 2013-2014, three mutations were found with synonymous replacement (G538G, Y500Y, R471R) and 7 mutations with a non-synonymous replacement, with a total of 9 mutated haplotypes, but none of them presented artemisinin-resistance in Southeast Asia. The study showed that gene changes in the kelch 13 region can occurred, but with any association to artemisinin-resistance [23].

Another report describes polymorphisms of the kelch13 gene in African parasite populations Authors declared that numerous K13-propeller coding polymorphisms were found to circulate in Africa, but it wasn't observed any mutations associated with artemisinin resistance such as those reported in Southeast Asia. They resulted that these specific mutation are not prevalent in sub-Saharan Africa. Moreover all mutations occurring in K13 are not related to resistance to artemisinin, and secondary locus can be associated with a mutation that plays a role in resistance to artemisinin. Also researches in Southeast Asia stated that a group of genetic factors might be created artemisinin-resistant parasites [24-26]. In a study conducted in 2016, the polymorphisms of $P$. falciparum resistance to artemisinin were evaluated in K13 and PfATPase6 
genes in Bioco Island, Equatorial Guinea. The results showed that $2.04 \%$ of cases possess A578S non-synonymous mutation in the K13 but resistance to artemisinin did not spread in the region, While this SNP, K13-propeller A578S, was reported as the essential mutation involved in artemisinin resistance and accompanied with a high percentage of the artemisinin treatment failure in Southeast Asia [15]. The rapid detection of molecular networks from resistance to artemisinin or and identification of new therapies or development of new drugs can be an effective way to prevent emerging drug resistance in the parasite and entering the silence phase.

Finally, it is important to note that producing experimental resistance strain of $P$. falciparum parasite against antimalarial drugs in the laboratory, provides an invaluable opportunity for investigation the exact mechanism of parasite resistance to antimalarial drugs. Moreover, it offers an opportunity to investigate about new potential drugs with antimalarial activates. Furthermore, producing experimental resistant strains of malaria parasites facilitates considering different mechanisms of establishing resistance in the parasites, and even how such resistance can be broken down by novel antimalarial.

\section{Declarations}

\section{Ethics approval and consent to participate}

Ethical issues (Including plagiarism, misconduct, data fabrication and/or falsification, double publication, etc.) have been completely observed by the authors.

\section{Consent for publication}

Not applicable

\section{Availability of data and materials}

All data generated or analyzed during this study are included in this published article.

\section{Competing interests}

The authors declare that they have no competing interests

\section{Funding}

This study was funded by Tehran university of medical sciences grant No. 35924 .

\section{Authors' contributions}

Sahar Barati: conducting the laboratory tests.

Afsaneh Motevalli Haghi: responsible for coordination, implementation of the study, interpretation of results, editing the manuscript.

Mehdi Nateghpour: responsible for coordination, implementation of the study, interpretation of results, editing the manuscript.

Zahra Zamani:advisor for continuous culture, revising the manuscript. 
Sadegh Khodaveisi: advisor for computational analysis.

Soudabeh Etemadi conducting the laboratory tests.

All authors read and approved the final manuscript.

\section{Acknowledgements}

We would like to thank Mrs. L. Farivar and Mrs.Z.Talaee for their useful collaboration in this study.

\section{References}

1. White NJ, Breman JG: Malaria and babesiosis: diseases caused by red blood cell parasites. Harrisons Principles of Internal Medicine 2001, 1:1203-1212.

2. Fèvre E, Barnish G, Yamokgul P, Rooney W: Sensitivity in vitro of Plasmodium falciparum to three currently used antimalarial drugs on the western border of Thailand. Transactions of the Royal Society of Tropical Medicine and Hygiene 1999, 93:180-184.

3. Hay SI, Guerra CA, Tatem AJ, Noor AM, Snow RW: The global distribution and population at risk of malaria: past, present, and future. The Lancet infectious diseases 2004, 4:327-336.

4. Organization WH: World malaria report 2017. 2017.

5. Sharma Y: Genetic alteration in drug resistance markers of Plasmodium falciparum. Indian Journal of Medical Research 2005, 121:13.

6. Witkowski B, Lelièvre J, Barragán MJL, Laurent V, Su X-z, Berry A, Benoit-Vical F: Increased tolerance to artemisinin in Plasmodium falciparum is mediated by a quiescence mechanism. Antimicrobial agents and chemotherapy 2010, 54:1872-1877.

7. Ariey F, Witkowski B, Amaratunga C, Beghain J, Langlois A-C, Khim N, Kim S, Duru V, Bouchier C, Ma L: A molecular marker of artemisinin-resistant Plasmodium falciparum malaria. Nature 2014, 505:50.

8. Dondorp AM, Nosten F, Yi P, Das D, Phyo AP, Tarning J, Lwin KM, Ariey F, Hanpithakpong W, Lee SJ: Artemisinin resistance in Plasmodium falciparum malaria. New England Journal of Medicine 2009, 361:455-467.

9. Trager W, Jensen JB: Human malaria parasites in continuous culture. Science 1976, 193:673-675.

10. Nateghpour $\mathrm{M}$, Ward $\mathrm{S}$, Howells R: Induction of drug resistance in Plasmodium falciparum: an intermittent drug exposure method. Iranian Journal of Public Health 1998:43-60.

11. Chatterjee M, Ganguly S, Saha P, Bankura B, Basu N, Das M, Guha SK, Maji AK: No polymorphism in Plasmodium falciparum K13 propeller gene in clinical isolates from Kolkata, India. Journal of pathogens 2015, 2015.

12. Mukherjee A, Bopp S, Magistrado P, Wong W, Daniels R, Demas A, Schaffner S, Amaratunga C, Lim P, Dhorda M: Artemisinin resistance without pfkelch13 mutations in Plasmodium falciparum isolates from Cambodia. Malaria journal 2017, 16:1-12.

13. White NJ: Artemisinin resistance-the clock is ticking. Lancet 2010, 376.

14. Eboumbou Moukoko CE, Huang F, Nsango SE, Kojom Foko LP, Ebong SB, Epee Eboumbou P, Yan H, Sitchueng L, Garke B, Ayong L: K-13 propeller gene polymorphisms isolated between 2014 and 2017 from Cameroonian Plasmodium falciparum malaria patients. PloS one 2019, 14:e0221895.

15. Li J, Chen J, Xie D, Eyi UM, Matesa RA, Obono MMO, Ehapo CS, Yang L, Yang H, Lin M: Limited artemisinin resistanceassociated polymorphisms in Plasmodium falciparum K13-propeller and PfATPase6 gene isolated from Bioko Island, Equatorial Guinea. International Journal for Parasitology: Drugs and Drug Resistance 2016, 6:54-59. 
16. Kwansa-Bentum B, Ayi I, Suzuki T, Otchere J, Kumagai T, Anyan WK, Osei JH, Asahi H, Ofori MF, Akao N: Plasmodium falciparum isolates from southern Ghana exhibit polymorphisms in the SERCA-type PfATPase6 though sensitive to artesunate in vitro. Malaria journal 2011, 10:187.

17. Alker AP, Lim P, Sem R, Shah NK, Yi P, Bouth DM, Tsuyuoka R, Maguire JD, Fandeur T, Ariey F: Pfmdr1 and in vivo resistance to artesunate-mefloquine in falciparum malaria on the Cambodian-Thai border. The American journal of tropical medicine and hygiene 2007, 76:641-647.

18. Cui L, Wang Z, Miao J, Miao M, Chandra R, Jiang H, Su Xz, Cui L: Mechanisms of in vitro resistance to dihydroartemisinin in Plasmodium falciparum. Molecular microbiology 2012, 86:111-128.

19. Witkowski B, Khim N, Chim P, Kim S, Ke S, Kloeung N, Chy S, Duong S, Leang R, Ringwald P: Reduced artemisinin susceptibility of Plasmodium falciparum ring stages in western Cambodia. Antimicrobial agents and chemotherapy 2013, 57:914-923.

20. Straimer J, Gnädig NF, Witkowski B, Amaratunga C, Duru V, Ramadani AP, Dacheux M, Khim N, Zhang L, Lam S: K13propeller mutations confer artemisinin resistance in Plasmodium falciparum clinical isolates. Science 2015, 347:428431.

21. Rocamora F, Zhu L, Liong KY, Dondorp A, Miotto O, Mok S, Bozdech Z: Oxidative stress and protein damage responses mediate artemisinin resistance in malaria parasites. PLoS pathogens 2018, 14:e1006930.

22. Chavchich M, Gerena L, Peters J, Chen N, Cheng Q, Kyle DE: Role of pfmdr1 amplification and expression in induction of resistance to artemisinin derivatives in Plasmodium falciparum. Antimicrobial Agents and Chemotherapy 2010, 54:2455-2464.

23. Huang B, Deng C, Yang T, Xue L, Wang Q, Huang S, Su X-Z, Liu Y, Zheng S, Guan Y: Polymorphisms of the artemisinin resistant marker (K13) in Plasmodium falciparum parasite populations of Grande Comore Island 10 years after artemisinin combination therapy. Parasites \& vectors 2015, 8:634.

24. Taylor SM, Parobek CM, DeConti DK, Kayentao K, Coulibaly SO, Greenwood BM, Tagbor H, Williams J, Bojang K, Njie F: Absence of putative artemisinin resistance mutations among Plasmodium falciparum in sub-Saharan Africa: a molecular epidemiologic study. The Journal of infectious diseases 2014, 211:680-688.

25. Kamau E, Campino S, Amenga-Etego L, Drury E, Ishengoma D, Johnson K, Mumba D, Kekre M, Yavo W, Mead D: K13propeller polymorphisms in Plasmodium falciparum parasites from sub-Saharan Africa. The Journal of infectious diseases 2014, 211:1352-1355.

26. Maïga-Ascofaré 0 , May J: Is the A578S single-nucleotide polymorphism in K13-propeller a marker of emerging resistance to artemisinin among Plasmodium falciparum in Africa? The Journal of infectious diseases 2015, 213:165166.

\section{Figures}



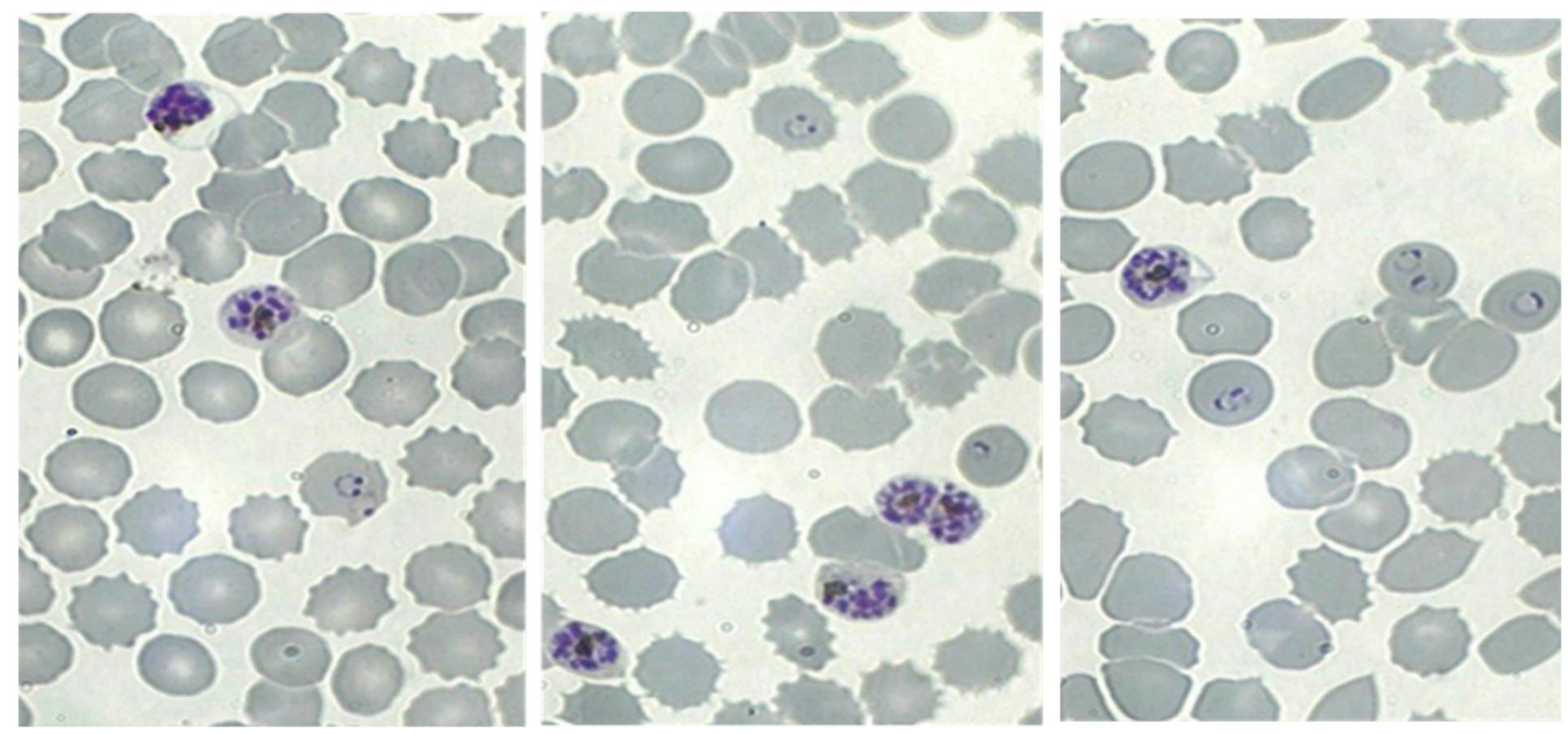

\section{Figure 1}

Ring and schizont stages of P. falciparum 3D7 in continuous culture (thin blood smears).
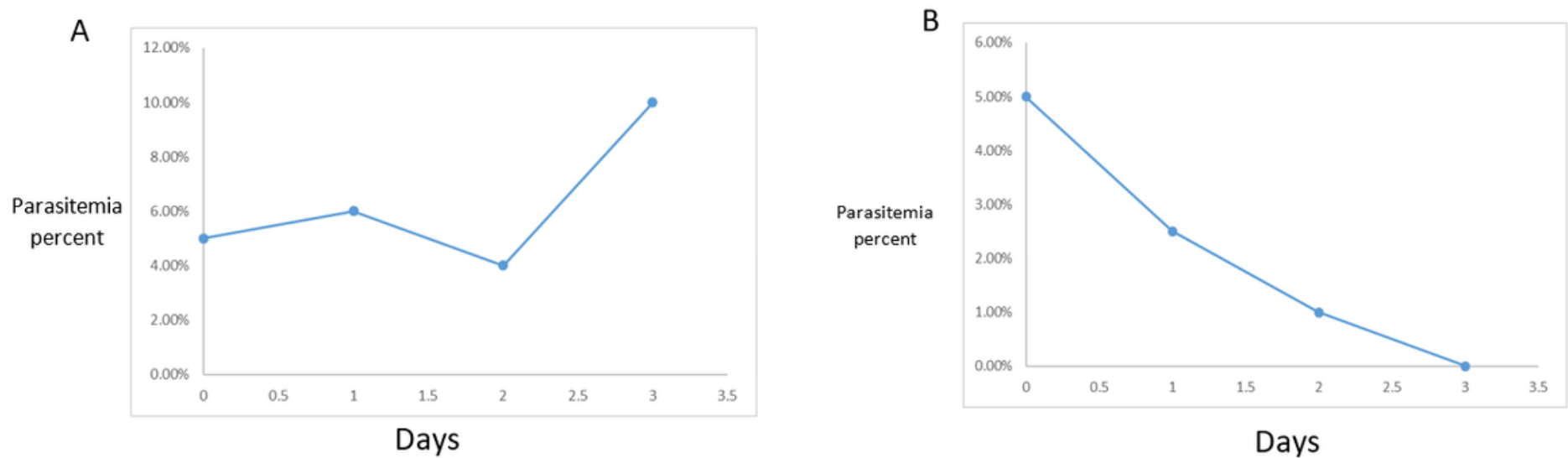

\section{Figure 2}

Determination of artesunate lethal dose. The control group (A) (non-receiving drug) and test group (B) (plus 10-2 mol/l artesunate, lethal dose) of P. falciparum 3D7 continues culture. 


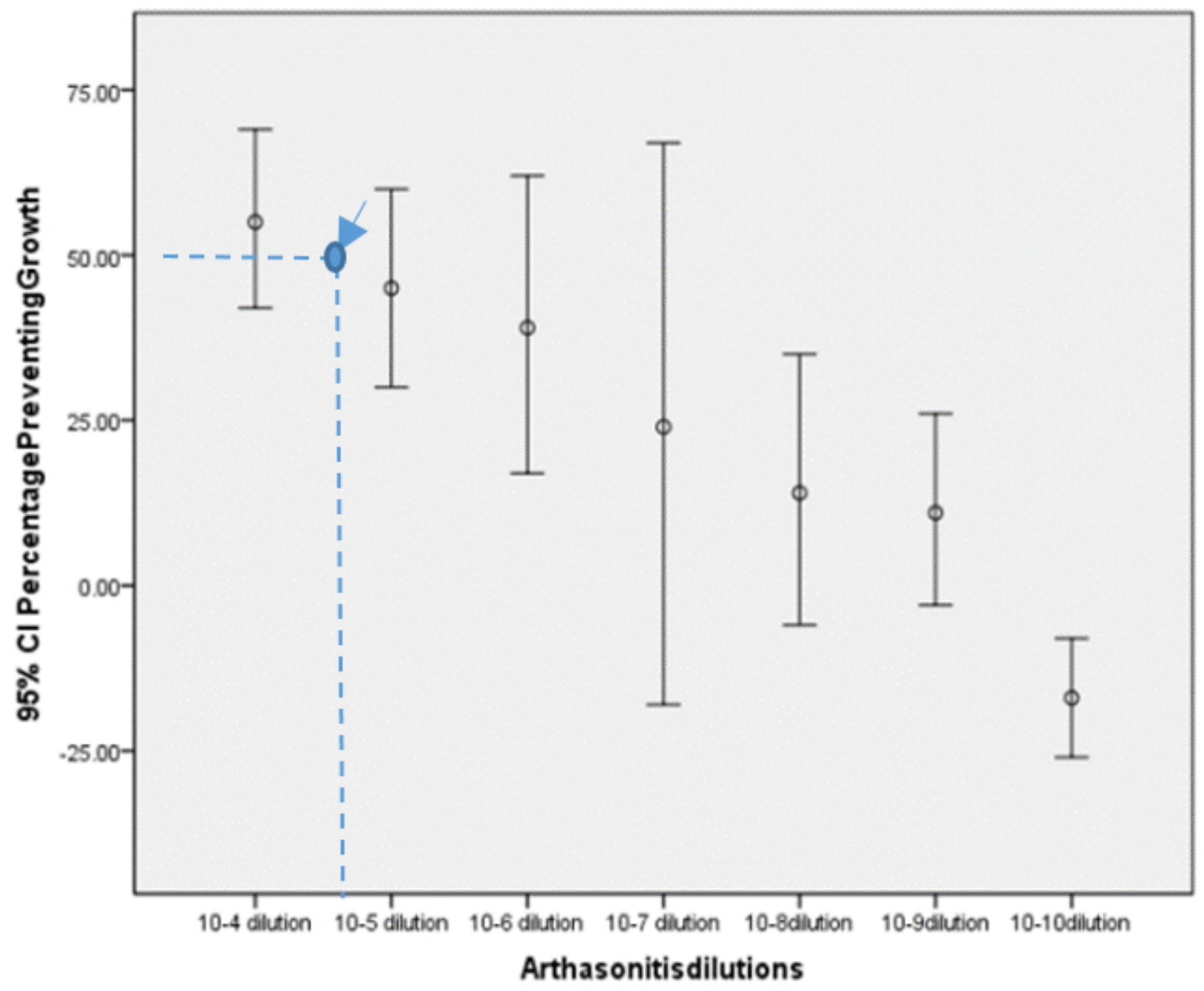

Figure 3

IC50 determination using different concentrations of artesunate by SPSS software

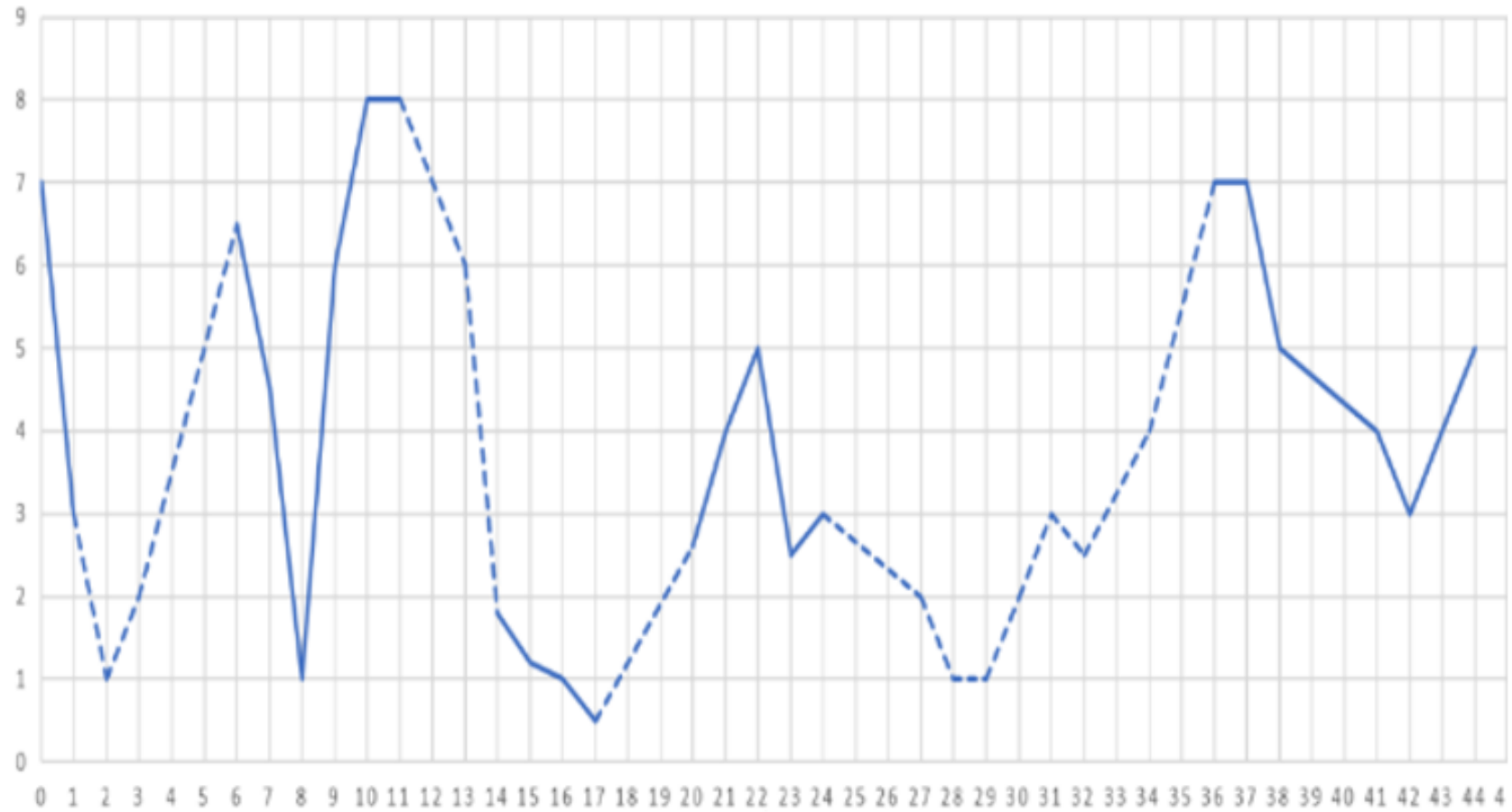




\section{Figure 4}

Sensitivity reduction for different concentration of artesunate on P. falciparum 3D7, the test was started when parasitemia percentage was 6-7\%.

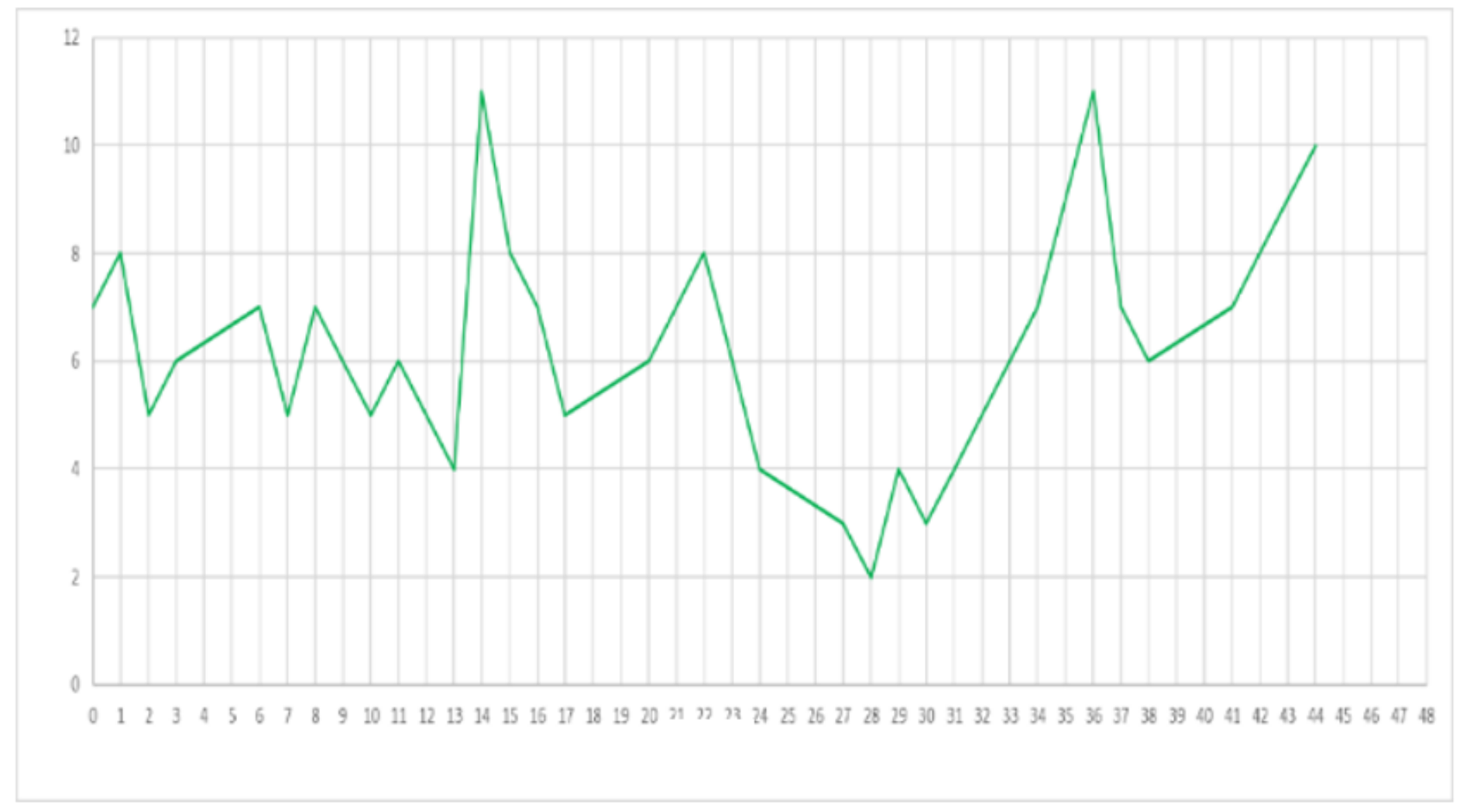

\section{Figure 5}

Control group of P.falciparum 3D7, control group included only the culture medium and parasite, which was not affected by any drug.

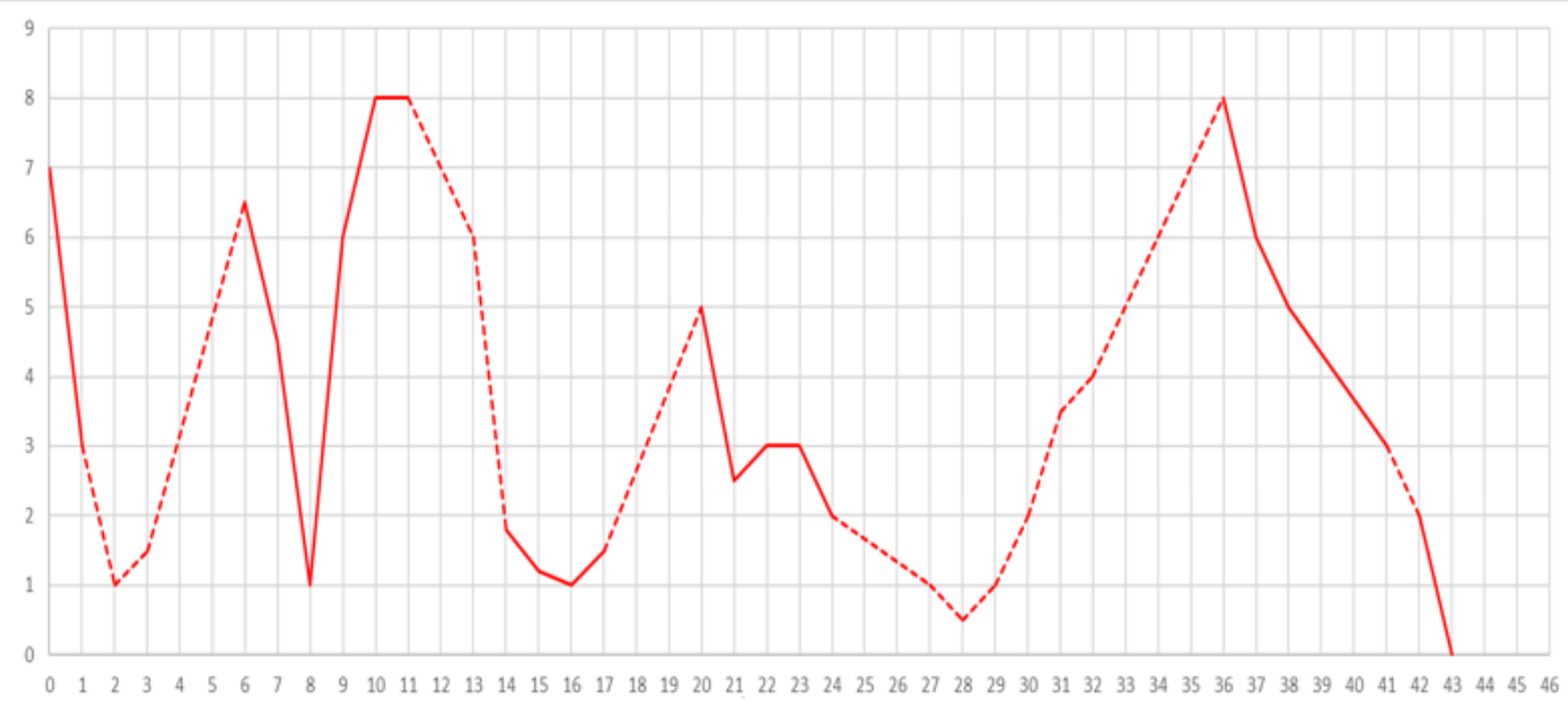




\section{Figure 6}

Death curve of P.falciparum 3D7, following the exposure of artesunate.

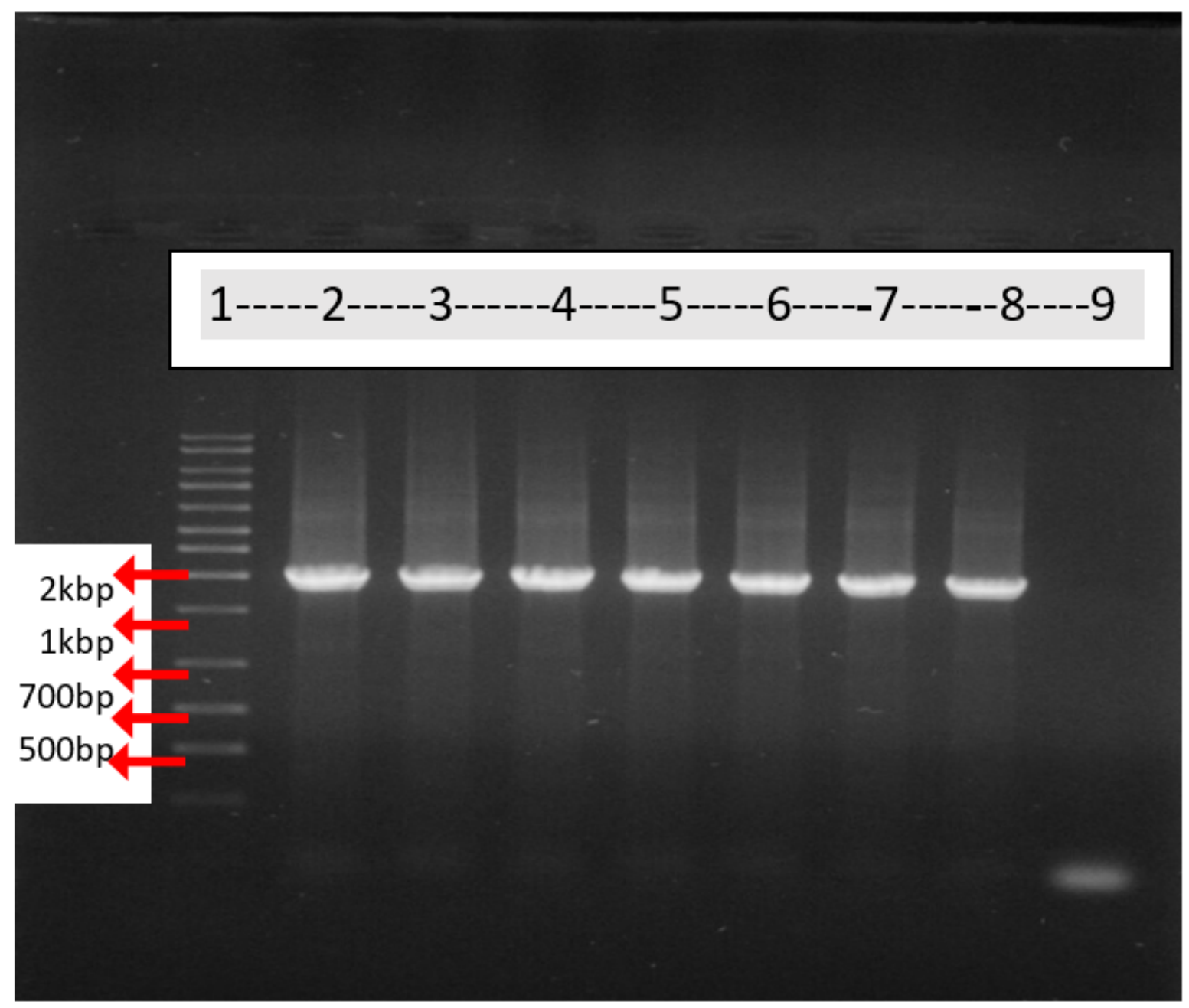

\section{Figure 7}

Gel electrophoresis of PCR products corresponding to P.fkelch13 gene. A 2097 bp band was yield at the first round. Samples were included: No. 1: DNA size Marker 1kb, No. 2: proliferation of P.f kelch13 gene from P. falciparum 3D7 susceptible to artesunate drug. Nos. 3, 4, 5, 6: proliferations of P.f kelch13 gene from four new strains reduced sensitivity to artesunate with concentration of 10-5 mol/l, 10-4 mol/l, 10-3 mol/l, 10-2 mol// respectively. No.7: proliferation of P.f kelch13 gene from a patient's blood sample with artesunate-resistant reaction. No. 8: Positive control. No. 9: Negative Control. 


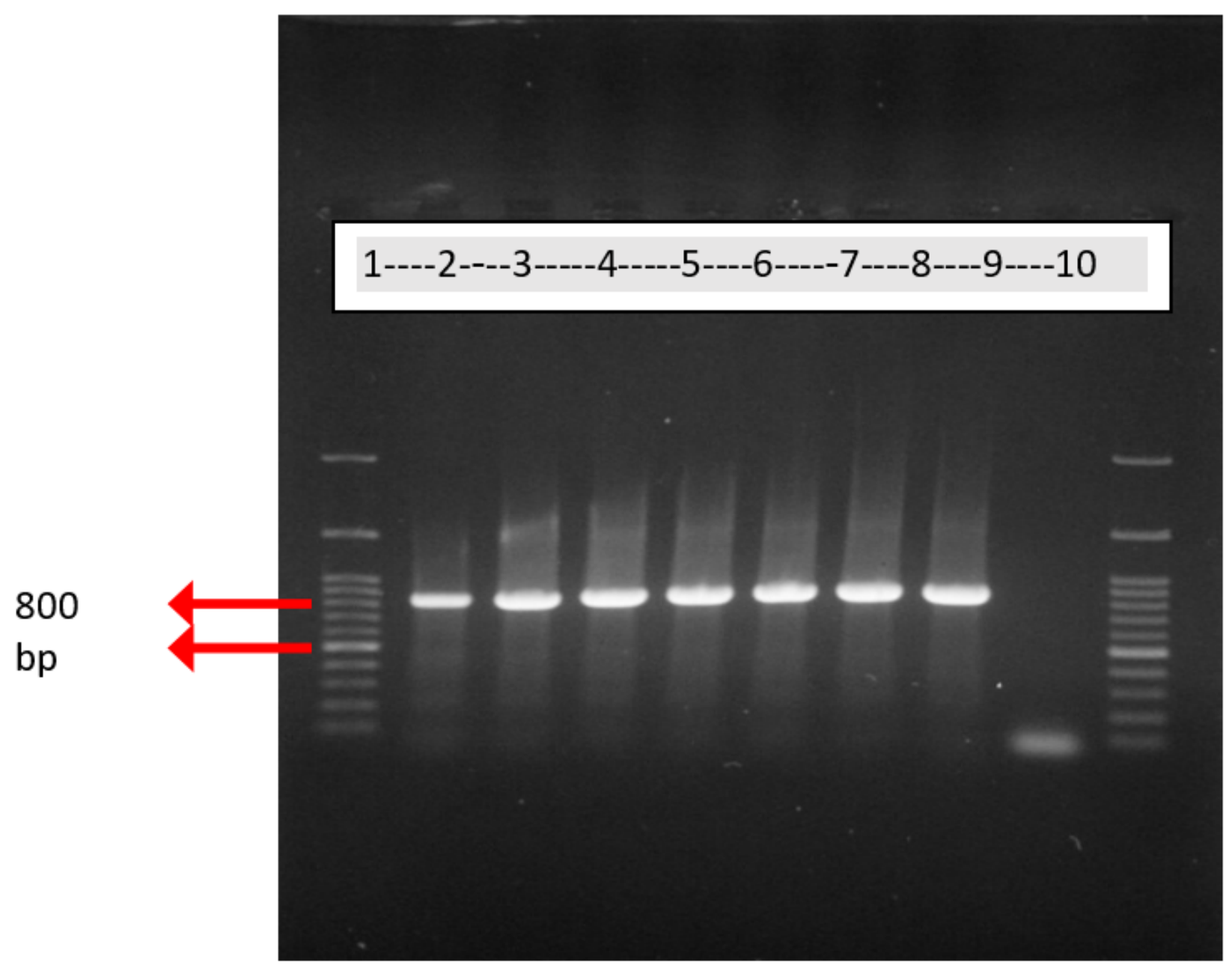

Figure 8

amplification of PCR products from the second round: an $849 \mathrm{bp}$ band related to P.fkelch13 gene from plasmodium falciparum 3D7 was yield on 1\% agarose gel. Nos. 1 \& 10: DNA marker size 100bp, No. 2: amplification of P.fkelch13 gene from Plasmodium falciparum susceptible to artesunate. Nos. 3, 4, 5, 6: proliferations of P.f kelch13 gene from four new strains reduced sensitivity to artesunate with concentration of $10-5 \mathrm{~mol} / \mathrm{l}, 10-4 \mathrm{~mol} / \mathrm{l}, 10-3 \mathrm{~mol} / \mathrm{l}, 10-2 \mathrm{~mol} / \mathrm{l}$ respectively. No.7: proliferation of P.f kelch13 gene from a patient's blood sample with artesunate-resistant reaction. No. 8: Positive control. No. 9: Negative Control.

MH796124.1 MH746930.1 MH796123.1

MH796124.1 MH7 46930.1 MH796123.1
СтTTTGATAАTAAAATTATGTCATTGGTGGAACTAATGGTGAGAGATTAAATTCTATTG 478 CTTTTGATAATAAAATTTATGTCATTGGTGGAACTAATGGTGAGAGATTAAATTCTATTG 478 СTTTTGATAATAAAATTATGTCATTGGTGGAACTAATGGTGAGAGATTAAATTCTATTG 480

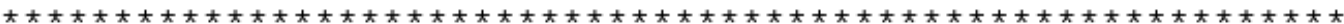

AAGTATATGAAGAAAAAATGAATAAATGGGAACAATTTCCATATGCCTTATTAGAAGCTA 538 AAGTATATGAAGAAAAAATGAATAAATGGGAACAATTTCCATATGCCTTATTAGAAGCTA 538 AAGTATATGAAGAAAAAATGAATAATGGgAACAATTCCATATGCCTTATTAGAAGCTA 540

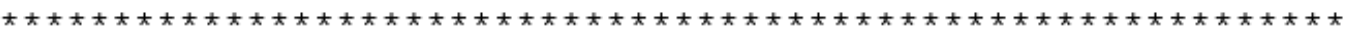

\section{Figure 9}

Clustal multiple sequence alignment showed 100\% Identity for Pfkelch13 Ar-2, Pfkelch13 Ar-4 and sensitive strain samples. 


\section{Supplementary Files}

This is a list of supplementary files associated with this preprint. Click to download.

- refs.myd

- refs.frm 